\title{
LXXIX. Examination of a fourth experiment adduced by Prof. Faraday in support of M. de la Rive's theory, and regarded by Dr. Fusinieri to be demonstrative
}

\section{Dr. Stephen Marianini}

To cite this article: Dr. Stephen Marianini (1841) LXXIX. Examination of a fourth experiment adduced by Prof. Faraday in support of M. de la Rive's theory, and regarded by Dr. Fusinieri to be demonstrative , Philosophical Magazine Series 3, 18:120, 529-544, DOI: 10.1080/14786444108650345

To link to this article: http://dx.doi.org/10.1080/14786444108650345

$$
\text { 曲 Published online: } 01 \text { Jun } 2009 .
$$

Submit your article to this journal $₫$

\section{山 Article views: 3}

Q View related articles ¿ 
THE

LONDON, EDINBURGH AND DUBLIN

PHILOSOPHICAL MAGAZINE

AND

JOURNAL OF SCIENCE,

SUPPLEMENT то VOL. XVIII. THIRD SERIES.

LXXIX. Examination of a Fourth Experiment adduced by Prof. Faraday in support of M. de la Rive's Theory, and regarded by $\mathrm{Dr}$. Fusinieri to be demonstrative. By $\mathrm{Dr}$. Stephen Marianini, Acting Professor of Particular and Experimental Physics in the University of Modena, \&c.

[Continued from p. 202.]

Second Article. Examination of the Observations recently made by Prof. de la Rive in support of his Theory, and which Dr. Fusinieri has considered sufficient to answer the preceding Objections*.

X. D. AMBRogio FUSINIERI seems to blame me for not having alluded, in my fourth Memoirt, to the interesting work of M. de la Rive, entitled, "Inquiry into the Cause of Voltaic Electricityt." I did not instantly allege in my excuse the having written and sent the said memoir to the Secretary of the Italian Society of Sciences, some time previous to my becoming acquainted with the said work, which had been kindly presented to me only in the November of 1836, by my illustrious colleague, Prof. de la Rive, this circumstance having little interest for the scientific, for whom I intend to write, and still less for science; but I applied myself instead to study the work itself, as soon as I was able to do so.

Whoever does not know this production of M. de la Rive, no doubt, on hearing how Signor Fusinieri speaks of it, would believe that in the same manner in which, in my second memoir, I had examined all the arguments and principal experiments brought forward by the Professor of Geneva in support of his theory, and had shown the insufficiency of them with other experiments; so also M. de la Rive might undertake to examine my arguments, and might show the erroneousness of them ; but what would be his surprise, when setting himself to read this work (without doubt having other claims to interest),

* Annali de Scienze del Regno Lombardo-Veneto, Bimestre iv., 1837, p. $192 . \quad+$ Ibid. $\$$ Recherches, \&c.

Phil. Mag. S. 3. Vol. 18. No. 120. Suppl. July 1841. 2 M 
he should see that the same facts are reproduced which were already published by him in 1828, when he wished to found his theory; and of the many arguments and experiments brought forward by me, he only speaks of two or three secondary in importance, and not with the profundity which one might expect from so distinguished a physicist !

In the first part of my said memoir I treat of the influence which voltaic currents exercise in changing the relative electromotive property of the metals, and of that which is exercised upon them by the liquid conductors, in which are immersed the metals themselves; and I established some facts which ought to serve as the rationale of some experiments produced by $M$. de la Rive as inexplicable except upon his theory. But of these we will not speak here. Nor let any one interpret this silence into denial or disapprobation, since the same M. de la Rive, in his historical sketch of the principal facts discovered in electricity, makes mention of all these, and not only without starting a doubt of them, but also with expressions very flattering to $\mathrm{me}^{*}$.

In the second part of that memoir I undertake to show the insufficiency of the theory of $M$. de la Rive to explain the phænomena of the electromotors, as well simple as complex.

Treating of the simple electromotors, and of the case in which the two plates are immersed in the same liquid, M. de la Rive adduced in support of his theory that an electric current is produced when there are immersed in one liquid two portions of the same metal susceptible of being attacked by it. And I observed that if these two portions have some heterogeneity, the fact accords with the theory of Volta; if not, there is no theory, either chemical or physical, which can explain it. (Memoir above mentioned, $\oint$ XXIII.)

M. de la Rive observed that if a voltaic pair of copper and tin is immersed in an acid or saline solution, the tin is positive; and if it immersed in ammonia, the copper is positive, because more acted upon by the liquid than the tin. And I showed that this second part of the experiment is not true, except after the ammonia may have altered, in a contrary sense, the electrotism of the two metals, and that, in consequence, it contradicts the theory of M. de la Rive, instead of supporting it. The same observations I made upon the similar experiment of M. de la Rive, with copper and iron. ( $\mathrm{XXIV.)}$

Another fact which $M$. de la Rive adduced was, that on immersing iron and lead in concentrated nitric acid, the iron in the first moment is negative, "because (it was said) there

* Esquisse historique des principales découvertes faites dans l'électricité depuis quelques années. Par M. Auguste de la Rive. Genève, 1833, 
was not yet any chemical action;" but if one waits until the chemical action shall commence, or if the part of the plate of iron immersed in the liquid is exposed for a moment to the air, which quickly determines the action, that iron itself becomes positive. And $I$ in the first place inquired whence might arise the negative electrization in the iron, and consequently positive in the lead, in the first instant that the copper is immersed, if it had yet no chemical action. And how stands now the theory of $M$. de la Rive? In the second place I demonstrated that the nitric acid increases the electrotism both in the iron and the lead, but more in the latter than in the former. I showed, in the third place, that it was an error to believe that causing the iron to be exposed to the air might be the cause by which it was electrified positively, on again putting it into the acid, because the cause of this positive electrization of the iron was the alteration which the lead suffered in the acid in which it was left immersed whilst the iron was kept in the air. And I proved, lastly, that to explain those experiments by the chemical theory, it is necessary to suppose now that the action of the acid renders the iron positive with respect to the lead, now that it renders it negative; now we must suppose that the action of the acid may be less forcible in the first instants upon the iron than upon the lead; now we must suppose the contrary. ( $\S$ XXVII.)

Another experiment quoted by $M$. de la Rive was, that two plates, the one of gold, the other of the purest platina, being fixed to the extremity of the galvanometric wire, and immersed in the pure nitric acid, a very sensible current took place when a drop of hydrochloric acid was added to the said liquid. And I demonstrated by ten experiments, first, that the nitric acid, mixed with very little hydrochloric acid, increases the relative electromotive faculty both in the gold and in the platina, but more in the latter than in the former; secondly, that such phænomena are not derived from electricity immediately developed by the chemical action; thirdly, that it is impossible to explain all the phænomena which are obserred in these experiments by the new theory. $(\$ \mathrm{XXV}$.)

And to all these facts stated in the first section of the second part of my before-mentioned memoir, and which contradict the chemical theory of electromotors, what arguments does M. de la Rive oppose? Perhaps Signor Fusinieri believes that the silence of the learned Genevan is sufficient confutation, or that he may have replied sufficiently in saying that the electricity developed by the chemical action is not always in proportion to the action itself. I should sooner have expected that Signor Fusinieri might have seen in this propo. 
sition a proof of the persuasion which $M$. de la Rive begins to entertain that his theory is not sufficient to explain the phænomena of the electromotors, if my experiments are true; though, if Dr. Fusinieri would do them the honour to repeat them, I doubt not that he would quickly be persuaded that that modification is not sufficient for the theory; but it would be necessary to add, that sometimes the electrization is in an inverse ratio to the force of the chemical action, that is, to the energy of the cause from which it is pretended to be derived. But we are here at a point of my memoir which $M$. de la Rive discusses in his Recherches, p. 125.

$X I$. In describing the experiment of which I have now spoken, M. de la Rive remarked that these plates of gold and pure platina, immersed in the pure nitric acid, produce no current whatever: and I said I had obtained the same phænomena with the nitric acid as with the acid itself mixed with a little hydrochloric acid, except that the galvanometric deviations were somewhat less. Now, however, M. de la Rive repeats the same thing; that is, the not having obtained a similar current in making use of the pure nitric acid; and Signor Fusinieri rather inclines to believe in the result of De la Rive, having himself made the experiment with another scientific man; and he thinks the observation just, which the same Genevan physicist then adds, namely, that as I experimented in Venice, it was a matter of difficulty that the nitric acid should be entirely free from hydrochloric. And here it vexes me that I must point out to Signor Fusinieri that this difficulty also presented itself to me, as is seen in the same page in which I speak of this experiment; and not only did I see the objection, but also removed it, by proving that by leaving the nitric acid exposed for a long time to the Venetian air, instead of acquiring to a much greater degree the aptitude to cause that current, it went on losing it; that is, on the contrary, it went on losing the power of altering to positive the relative electromotive faculty of the platina and the gold so far as to acquire the opposite property. ( $\$$ XXVI.)

But there is yet more. Is it then true that there is that difference in the facts, which Dr. Fusinieri remarks in this proposition, namely, that De la Rive may not have seen in immersing the gold and the platina in the nitric acid, the small electric currents seen by me? And do we not read at the eleventh page of his Recherches, that in the act of immersing that pair in the nitric acid there are seen slight galvanometric deviations? "Du moins (these are his own words) le léger courant que l' on aperçoit au premier moment de l'immersion, n'est pas plus fort que celui qui a lieu quand on se sert de 
deux lames homogènes de platine, et il est dû aux impuretés dont il est impossible de préserver complètement les surfaces métalliques; aussi disparait-il très-promptement, et quoique les deux métaux restent dans le liquide, on n'en voit bientôt plus aucune trace."

Then also the learned Genevan sees the voltaic current on immersing in the pure nitric acid the gold and the platina fixed to the ends of the galvanometric wire: he observes that the current itself is not stronger than that produced by the two homogeneous plates of platina; and he attributes it to the impurities, from which he says it is impossible completely to preserve metallic surfaces. And in proof that this and no other is the cause of that current, M. de la Rive adduces the fact that it disappears immediately, and that however long the two metals may remain in the liquid, in a few moments there is no more trace of it.

The difference, then, is not in the fact, but in the manner of studying and interpreting it. M. de la Rive not being able to persuade himself that there can be an electric current without chemical action, and insisting that neither the gold nor the platina can be injured by the nitric acid, supposes it impossible entirely to purify the surfaces of the two metals. Instead of this, I imagine that the current is produced because the platina touches the gold metallically, by means of the galvanometric wire, and is immersed with it in a liquid. If the current is weak, it is because the metals are sufficiently near in the voltaic scale; if it vanishes, or rather, if it becomes sensibly weaker in a short time, it is because the current itself increases the electromotive faculty of the gold, and diminishes that of the platina, so that in a short time the two metals become almost homogeneous in the voltaic sense of that term.

M. de la Rive attributes the vanishing of the current to the disappearance of the impurities from the surfaces of the two metals. But I shall here ask if it is desired that the nitric acid may destroy those impurities by means of the little current which is developed, or that it may be destroyed independently of it. In the first case, I shall inquire how it happens that if the gold is immersed in the acid a moment before the platina, the galvanometric deviation is extremely weak, and sometimes even nothing. In the second case, the current which is observed when the two plates are allowed to remain imniersed in the acid for some time before putting them in communication with each other by means of the wire of the galvanometer, will have to be explained.

There is still a remark to make respecting the disappearance of the current, which $M$. de la Rive declares to happen 
a few moments after the circuit is complete; so that to see that current disappear, two conditions are necessary. The first is, that the experiments may be made with a galvanometer not very sensitive, that is, such as may not indicate the current itself, except by one or two degrees of deviation. The second is, that the two metals may be immersed in the acid whilst they are still in communication with each other, exactly as M. de la Rive conducts the experiment. But if use is made of a galvanometer rather sensitive, such, for example, as may show the current by a deviation of ten or more degrees, it is very true that in a few moments the force of the current is much weakened; but it does not fail to be visible with some degree of deviation, even after more than a minute; so that the deviation is strong at first, but proceeds always more slowly in the times succeeding to the first immersion of the plates.

But experimenting with the galvanometer of moderate delicacy, if the plates are kept some little time in the liquid before completing the circuit with the galvanometric wire, it is seen that the current does not then cease so quickly; and it is stronger if more time is allowed to pass before closing the circuit itself.

The following are some experiments instituted already many times here in Modena, and with the galvanometer sufficiently sensitive, above mentioned.

A small plate of pure gold, and one of pure platina, being immersed for an instant in nitric acid, deprived entirely of hydrochloric acid whilst they remained in contact by means of the wire of the galvanometer, produced a deviation of $4^{\circ}$.

Two other similar plates being left immersed for half a minute, and then the circuit being closed for a moment, the deviation was of $10^{\circ}$.

The experiment being repeated with two other plates, and the circuit being completed for a minute after they were immersed, $25^{\circ}$.

Being left immersed for five seconds before completing the circuit, $75^{\circ}$.

The two small plates were kept at the distance of a centimeter from each other, and were immersed together in the liquid for a square centimeter of their surfaces.

The nitric acid increases the relative electromotive faculty of both those metals, but much more that of the platina than that of the gold, and thence may be drawn easily the explanation of these and of various other phænomena which are observed with the voltaic pair of platina and gold, when nitric acid is made use of for a moist conductor. (See my abovementioned memoir at $\$ \S X X V . X X V I$.) 
XII. I must not abandon this argument without making some observations respecting a singular proposition which is read towards the end of the tenth page of M. de la Rive's work, expressed in the following terms: "Lorsque le liquide dans lequel plongent les deux élémens du couple, est le même, il n'existe pas un seul cas dans lequel on ait vu le métal le moins attaqué être positif par rapport à l'autre."

Yet in the actual state of the science it is very easy to find many cases in which it is not yet known which element of the pair may be the most acted upon, although it may be undoubted that the pair itself produces a voltaic current. Which, for example, of the following substances-silver, gold, platina, carburet of iron, and peroxide of manganese-is most acted upon by distilled water? Yet, whatever pair may be made with the said metals, there is a current when it is immersed in the said liquid. If it be shown that charcoal, well freed from hydrogen and extinguished for some time, may be more acted upon by distilled water than the silver, gold and platina, by which it may have to electrify itself, how does it happen when positively voltaically united with those metals and inmersed in the same liquid? If it be shown that charcoal itself, when it is oxidated, may be less acted upon by distilled water than the noble metals, yet made into a pair with them it acquires negative electricity. If it be shown that tin may be more acted upon than copper, nickel, bismuth, cobalt, and iron, by the said liquid, yet tin becomes positive when immersed in such liquid voltaically united with any one of the said metals. Zinc united with cadmium is positive even in distilled water. Is it known which of the two is most acted upon by that fluid?

Here, then, are at least twenty cases, all observed by me separately, in which it is doubtful upon which of the two elements of the pair the liquid exercises the strongest chemical action; and it is very certain that one is electrified positively and the other negatively. And this number of doubtful cases is doubled when it is observed, that when making use of alcohol instead of distilled water, the effects are different, although the currents may in this case be weaker. The description of some experiments made with the said pairs may not be useless.

A plate of platina, and one of silver, fixed to the ends of the wire of the galvanometer, were immersed at the same time in rectified alcohol, at thirty-three degrees of the scale of Bauine, and there was a deviation of two degrees on the part of the platina. Both the plates touched the liquid with a surface of four square centimeters. 
A plate of gold with a surface of eight square centimeters, coupled with one of platina having a surface of one square decimeter, immersed in the said liquid, produced the deviation of a degree and a half, which indicated that the gold was positive in contact with the platina.

And thus, with any other of the above-mentioned pairs whatever, a current was obtained, which indicated that one of the metals was positive and the other negative.

XIII. But let us suppose that all these doubtful cases may not argue against the chemical theory; let us admit that the metal which shows itself positive may be also the most acted upon; and that if this is not yet demonstrated, it will be proved one day. What must we say of so many other cases, in which it is certain which of the two metals is the most acted upon, and equally certain that it is not electrified positively, as the new theory would assert?

Copper united with iron and immersed in ammonia is electrified negatively in the first moment of immersion. The same copper is charged also with negative electricity when united with tin and with lead, the pair being immersed in the same liquid; yet the copper is more acted upon by the ammonia than are the other two metals.

In the nitric and sulphuric acids, diluted or concentrated, are not copper and iron more acted upon than tin and lead? Yet copper as well as iron is electrified negatively when it is immersed in the said liquid, united with tin or lead.

Sulphuric acid, diluted by two hundred parts of water, acts less upon cobalt than the copper, polished antimony, and antimony slightly oxidated, which being immersed in the said acid, promotes effervescence. But the pairs, cobalt and copper, cobalt and antimony, immersed in the said acid, show the cobalt always positive.

Polished antimony, cobalt, bismuth, nickel, tin, and lead, are all less acted upon by acetic acid than copper is; yet they are all positive when, in voltaic association with copper, they are immersed in the said acid.

And here are twenty cases (and it is far from difficult to find others) in which the two elements of the pair are immersed in the same liquid, and the metal the least acted upon is positive with respect to the other. And it may be said that the experiments of the Genevan physicist must have been restricted within very narrow limits, if not one of these cases came under his notice; since, if the above facts are true, of which whoever will repeat them may assure himself, it appears to me impossible longer to admit, with $M$. de la kive, that "le sens du courant est toujours d'accord avec la théorie 
chimique, et que le métal sur lequel l'action chimique du liquide est la plus vive est toujours positif par rapport à l'autre." (From the work above cited, p. 14.)

I should believe, moreover, that one only of the abovementioned facts would suffice to justify the proposition which may be read at the end of $\S$ XXVII. of my memoir already quoted, "that the new theory is not sufficient to explain all the phanomena presented by simple electromotors, when the two plates of which they are formed are immersed in the same liquid."

XIV. Then when the two elements of the voltaic pair are immersed in different liquids, the cases are very many which contradict the new theory, and as elsewhere I have observed, they may be multiplied almost at the will of the experimenter. These were considered by M. de la Rive as apparent anomalies, and to explain them, I supposed that the two electric principles tend to reunite thenselves immediately in both liquids, that such reunion is more easy in the liquid which gives a positive action, and therefore the metal there immersed is negative.

Concerning this hypothetical explanation, after having pointed out in $\$ \mathbf{X X X}$. of my memoir three things to me incomprehensible in it, I demonstrated, with the assistance of experiment, that admitting those immediate reunions of the electric principles, very many facts are found in contradiction to the theory. And I concluded it "a thing not easy to be admitted that nature availed herself of those immediate recompositions of the two electric principles, except in those experiments rohich do not in any manner square with the new theory." And I terminated that section with some experiments derived from two then recent observations of Signor Becquerel, from which was inferred clearly "that in the voltaic pair is a cause which gives origin to electricity which cannot be confounded with the chemical action, and which is more porverful than it."

Now I would ask of Dr. Fusinieri what reply can be found in the work of M. de la Rive to these objections? Does he think it may suffice to find the same things (confuted by me) repeated in it, and without any notice whatever of the confutation? The silence of $M$. de la Rive would suffice certainly to reply where objections evidently erroneous were treated of; but where I bring forward experiments easy to be repeated, why had not Dr. Fusinieri, acute observer as he is, the curiosity to see them before pronouncing a judgment so disadvantageous with respect to them?

$X V$. Let us see, finally, what may be replied to the arguments with which I proved that the Delarivian theory was 
not sufficient to explain the phænomena of the complex electromotors.

The chemical theory being shown insufficient to explain the phænomena of the simple electromotors, the insufficiency as to the explanation of the phænomena of the complex electromotors was naturally deduced as a corollary from it; and I opposed besides the argument of the invariability of the tension, whatever may be the liquid in which the voltaic pairs are immersed, when neither their number nor their quality vary. And to anticipate the reply which would perhaps be made to that argument, that is, that although the different fluids may not exert equal chemical actions upon the voltaic pairs, yet the difference of the actions exerted upon the two elements of the pair being equal, the tension also must be invariable; I described an experiment made with two electromotors of eight pairs, which had equal tension, although the differences of the chemical actions exercised upon the two elements of each pair in each of the electromotors were any thing but equal; for in one all the plates were immersed in distilled water, and in the other the plates of zinc were immersed in distilled water, and those of copper in dilute sulphuric acid. ( $\$$ XXXIV.)

I undertook to examine also the truly ingenious method with which M. de la Rive attempted to explain the effects of the piles dependent upon the number of the pairs. To explain such effects, $M$. de la Rive supposes that the tendency which the two electric principles have to neutralize each other, acts so, that when the poles are not united by any conductor, it is the pile itself which serves them as a conductor, in producing the effect of one meeting the other. Thus the force of the tension will depend upon the greater or less facility which the voltaic apparatus shall present to the transmission of the two fluids. And since it is known that the greater the number of the plates to pass through, the more difficult is the transmission, so the electricity accumulated at one pole will not affect the condenser, except in so far as the pile itself shall be composed of such a number of pairs that the resistance opposed by the apparatus to the reunion of the two fluids shall be sufficiently great for the tension to become sensible.

And examining in the abstract this tendency, supposed by M. de la Rive, in the two electric fluids, to run to neutralize each other, even by the way which the electromotor itself offers to them, I permitted myself to suggest the following dilemma. Either this tendency exists also in the simple electromotors, that is formed by one pair alone, or it exists only in the complex electromotors. If it be admitted that such 
tendency exists even in one pair alone, it is not intelligible how it happens that the two electricities do not avoid passing the damp conductor, the metallic way, which is so much more conductive, being open to them. If, on the other hand, it be admitted that that tendency exists solely in the complex electromotor, then it is not intelligible how such a property arises in it, if the elements of which it is formed (which are also so many electromotors) are all without it. And to him who might have objected to such an argument, that the greater part of the two electric principles takes the metallic way to go to neutralize itself, and that adding pairs to pairs the tension increases, because the quantity which can pass through the electromotor is less; - to him who, I say, might have thus objected, I recalled the fact that the alternations of moist and metallic conductors diminish certainly the quantity of electricity which in a given time passes through the voltaic apporatus, but do not alter the tension.

I asked, in the second place, why the least indication may not be had of such currents in a direction contrary to the usual one. And finally, I found it difficult to be admitted that the two electric principles tend to retrocede in the pile in order to neutralize each other, whilst the virtue of the pile consists, on the contrary, in the tendency to accumulate one of such principles at the positive pole, and the other at the negative. ( $($ XXXV.)

The examination instituted by me respecting this manner of explaining the effects of the pile was not limited to the preceding abstract considerations, but was pursued also with experiments. If the tension of a pile is, as M. de la Rive says, relative to the greater or less difficulty which the pile itself opposes to the passage of the electricity, it will be sufficient, I said, to render the passage of the electric through the electromotor more difficult, to see the tension at the poles augmented; and therefore, after having watched the tension of a couronne de tasses, I disposed the pairs in other cups, so much more ample than the first, that the liquid stratum (which was, as in the first apparatus, rain water) interposed between each pair was about six times greater; and although here the resistance might be much greater which the electricity must encounter in moving itself in the apparatus, yet the tension was found to be not at all increased.

In the work of M. de la Rive no reply is given either to the experiments or to the reasonings here above-mentioned, with which I intended to prove the insufficiency of his theory in explaining the phænomena of the complex electromotors. 


\section{Prof. Marianini's Examination of an Experiment}

But behold us finally at some of my experiments, which the learned Genevan undertakes to examine.

Such experiments are only variations of the last one above recorded. In order to render the transmission of the electric fluid through the electromotor more difficult, I put between each two pairs several inactive arcs, that is, formed of one sole copper wire, and the tension was equal to that which was observed when the electromotor was arranged as usual. Sometimes in such experiments the transmissiveness of the apparatus becomes so much enfeebled, that there is no longer an indication of a current even to the galvanometer, as, for example, when I introduced between the three active pairs three hundred and ten inactive ones. Yet, notwithstanding, I found no difference in the tension of those three pairs from when they were arranged as usual, and the current excited by them did not pass through the water of three hundred other glasses, and the metallic arcs which put them in communication with each other. And since M. de la Rive said that the decomposing power of the electromotor apparatus must vary according to the relation which exists between the conductivity of the liquid which connects the two poles and the apparatus itself, I therefore brought forward experiments which showed that not to be true, because every time that I rendered the passage of the current sensibly more difficult, by adding now twenty, now forty, now a hundred inactive pairs, the decomposition taking place at the poles became always slackened. ( $\$$ XXXVI. and XXXVII.) And see how M. de la Rive discourses about these experiments at pages 151 and 152 of the work quoted.

"La principale objection du savant italien a été dirigée contre le principe que j'avais admis, savoir que les deux fluides électriques accumulés aux deux pôles de la pile peuvent se neutraliser directement par l'intermédiaire de la pile elle-même qui lui sert de conducteur. D'après ce principe, dit il, si l'on diminue la conductibilité de la pile on doit augmenter la tension de ses deux pôles; or, on ne produit pas ce dernier effet en interposant dans le liquide qui sépare les couples, un plus ou moins grand nombre de diaphragmes de cuivre, interposition, qui cependant doit diminuer la conductibilité de la pile. Il y a plus; cette interposition non seulement n'augmente pas la tension, mais elle diminue même le pouvoir chimique de la pile dans la décomposition de l'eau; cependant lorsque les pôles sont réunis par un conducteur imparfait, s'il est vrai que la proportion d'électricité qui passe par ce conducteur et par la pile dépende de leur conductibilité rélative, il doit en pas- 
ser d'autant plus à travers le conducteur que la pile conduit plus mal. A l'appuis de ces observations M. Marianini cite plusieurs experiences."

" Je suis tout-à-fait d'accord avec M. Marianini sur les consequences qu'il tire du principe que j'ai admis, mais je diffère sur l'application qu'il en fait; je reconnais avec lui que tout ce qui diminue la conductibilité de la pile, doit augmenter la tension de ses pôles pourvu qu'on n'altère en rien la quantité d'électricitè développée par chacun de ses couples; j'ai montré par des faits que c'était une condition indispensable. Mais la manière dont M. Marianini diminue la conductibilité de la pile, rentre-t-elle bien dans ce cas? Non, car le zinc et le cuivre entre lesquels il place les diaphragmes de cuivre ou de tout autre métal, n'étant plus dans les mêmes conditions que le zinc et le cuivre des autres couples, il est facile de comprendre que l'électricité positive du premier et la négative amenée par le second, se réunissent en beaucoup moins grande proportion à cause de la diminution de conductibilité qui résulte pour le liquide qui les sépare, de l'interposition des diaphragmes. Dès lors d'après la théorie que nous avons donnée, l'électricité libre de tous les autres couples diminue dans le même rapport que celle du couple que nous venons de considérer, de sorte que si d'une part les deux principes électriques accumulés aux deux pôles ont moins de facilité à se réunir d'autre part ils sont développées en moindre quantité. On conçoit que lorsqu'il s'agit de la tension, cas dans lequel l'élément du temps n'entre pour rien, puisque le condensateur reste en contact avec le pôle aussi long temps qu'on le veut, les deux effets que nous venons de signaler puissent se compenser: mais il ne peut en être de même pour les décompositions opérées par le courant et en général pour tous les effets dynamiques, car il n'y a pas de temps suffisant pour l'accumulation des deux principes électriques, et tout ce qui diminue la quantité de l'electricité libre dégagée en un temps donné par chaque couple, et par conséquent aux deux pôles, doit diminuer l'intensité des effets produits par la circulation de cette électricité."

M. de la Rive agrees, therefore, with me, that if the principle admitted by him be true, all that which diminishes the conductivity of the pile must augment the tension of the poles; but he suggests further, that what diminishes the conductivity of the pile may in no degree alter the quantity of electricity developed by each one of its pairs.

We will observe here directly, that before these instructions of M. de la Rive, the quantity of electricity developed by each couple was never said, that I know, to influence the tension. 
Every one knows that an electromotor of ten pairs has always the same tension, whether the plates are large or small, or even some small and others large. And it is known likewise, that the quantity of electricity developed varies much with the variation in the dimensions of all the pairs, or even only of some; the galvanometer's giving the most certain proofs of it.

But granted even that this might be, is it then true that the method by which I diminished the conductivity of the pile may not concern this case, that is, alter the quantity of electricity developed by each pair? M. de la Rive seems to say, that those pairs between the copper and the zinc, of which I placed metallic diaphragms, are not in the same condition with the other pairs. But the truth is, that it is not between the copper and the zinc of one pair that I placed the diaphragms; but between the zinc of one pair and the copper of another $I$ put some inactive pairs, that is, some arcs, formed of copper wire, which were immersed in cups containing the liquid conductor, as those which served for the active pairs. And this interpolation I did not make merely between some pairs; but in some experiments those arcs were interpolated between every one of them; so that all came to be in the same condition. If ever M. de la Rive should say that those pairs so interpolated are not in the same condition as those of another electromotor, where there may not be that interpolation of inactive pairs, and that, therefore, each pair of the interpolated electromotor developes less electricity than each one of the other, I would ask, rohence the electricity is developed according to the new theory? Is it not perhaps by the chemical action of the liquid upon the metal? and ought it not to be proportional to the difference of the actions exerted upon the zinc and upon the copper? Now, how do those inactive arcs interrupt the action of the liquid upon the elements of the pairs ; and then how do they alter the quantity of electricity developed?

And if yet it should be pretended that the presence of that inactive copper wire in the glass, where the zinc or the copper of a couple was immersed, might influence the action exerted by the liquid upon the zinc, or upon the copper of the same pairs; what influence will the copper wires placed in the other successive cups exert? The experiment shows that the tension is always the same, when placing one only of those inactive arcs between the pairs of one pile, as when placing six, eight, ten, or any other number whatever between them.

And these observations, made relative to tension, apply also, with the proper difference, to the decomposing power, which alway s diminishes, when, the other things being placed simi- 
larly, the conductivity of the pile (whatever may be the method) is diminished.

But wishing also to concede that those diaphragms or interpolated metallic arcs impart to the pairs the condition that M. de la Rive desires, how shall we explain the non-alteration of the tension, when the electromotor is rendered less conductive by disposing the pairs in much larger cups, by which the liquid strata, through which the electric fluid must pass, are more extended? This is the first and principal experiment which I oppose to $M$. de la Rive, regarding his manner of explaining the effects of tension and of decomposition, and of which he does not make mention.

I said that this was the principal of such experiments, because the insertion of liquid strata of great extent between the pairs occurring to me as difficult, I have applied to it again with series of metallic homogeneous arcs, knowing the diffculty which the electric current encounters in passing through alternate liquid and metallic conductors. Now, I have repeated that principal experiment also on a large scale, that is, with two electromotors; the one with small troughs, in which the plates were so disposed, that between the copper of one pair and the zinc of the next there was only a stratum of water of the size of one millimeter; and the other with great receivers, so that the stratum of water, which divided one pair from the other, was half a meter. The number of the pairs being equal in both apparatus, the tension was also equal in both.

I have tried also to oblige the current to pass through many cups of water connected by means of little siphons filled with the same liquid; but I did not succeed by this in obtaining increased tension.

Finally, in order not to vary in any way the conditions of the apparatus with respect to the development of the electricity according to the electro-chemical theory, I prepared a pile of three pairs, in one of which the plate of zinc communicated with that of copper by a small metallic wire a thousand meters in length, and in each of the other two the wire which connected the copper and the zinc was five hundred meters in length. The apparatus was arranged so that that communication could be easily taken away, and one substituted for it, not longer than four or five millimeters. Now, when the metallic communications between the zinc and the copper were formed of short wires, the deviation which the pile produced in the galvanometer was twenty degrees; and when the long were substituted for the short wires, it was only fourteen; yet the tension was always the same in both cases. 
544 Notices of the Labours of Continental Chemists.

For if M. de la Rive, in all these experiments, found the conditions always varied in order that the chemical action upon each couple might excite the same electricity, I should desire very much that he would point out at least one experiment in which the couples remaining equal both in number and quality, but the conductivity of the pile varying, the tension might be seen likervise to vary. This experiment $I$ expected to find described in the above-mentioned work, after his having said that he agreed with me, that all which diminishes the conductivity of the pile, must, according to his theory, augment the tension of the poles; I expected also, that he would only disagree with me in regard to the mode of diminishing the said conductivity. I find instead, that M. de la Rive says, that in my method of weakening the conductivity of the pile, if on one part the two electric principles met together at the poles have less facility of reuniting themselves, they are developed in less quantity. But truly he should agree that they might be developed not in less quantity, although with less tension, that the electric principles might show themselves unvaried in the tension at the poles of the pile, notwithstanding that its conductivity might vary.

[lo be continued.]

LXXX. Notices of the Results of the Labours of Continental Chemists. By Messrs. W. Francis and H. Croft.

[Continued from p. 442.]

Action of Chlorine on Oxalic Zther.

MALAGUTI has published a series of interesting experiments on the action of chlorine on oxalic æther. He has succeeded in preparing a chloroxalic æther, in which the entire quantity of the hydrogen of oxalic æther is replaced by an equivalent quantity of chlorine, $\mathrm{C}^{10} \mathrm{Cl}^{10} \mathrm{O}^{4 *}$. The resulting chloroxalic æther affords with liquid ammonia oxamid, with gaseous ammonia chloroxamethane, a body comparable in every respect to oxamethane. The chloroxamethane is converted by the action of liquid ammonia into chloroxalovinate of ammonia, from which may be obtained the chloroxalovinic acid, which differs from oxalovinic acid solely from its containing chlorine in the place of hydrogen. This acid may be obtained in an anhydrous state by the action of alcohol on chloroxalic æther, which may again be made to give birth to a chlorated acid, especially by the oxidizing action of alkalies. One of the most remarkable

* [The system of formulx in this abstract is different from that in the former abstracts; the small French value for carbon having been assumed.] 